\title{
Development and Evaluation of Sampling Methods for Fields with Infestation Foci of Potato Cyst Nematodes (Globodera rostochiensis and G. pallida)
}

\author{
T. H. Been and C. H. Schomaker
}

Plant Research International, P.O. Box 16, NL-6700 AA Wageningen, the Netherlands. Accepted for publication 3 March 2000.

\begin{abstract}
Been, T. H., and Schomaker, C. H. 2000. Development and evaluation of sampling methods for fields with infestation foci of potato cyst nematodes (Globodera rostochiensis and G. pallida). Phytopathology 90:647-656.

A computer program, SAMPLE, was developed to evaluate existing and create new sampling methods for the detection of infestation foci of the potato cyst nematode (Globodera rostochiensis and G. pallida). By combining a model for the medium-scale distribution of cysts that provides the expected population densities at each position within the focus and a model for the small-scale distribution within square meters, sampling procedures can be simulated. The importance of the parameters of the two distribution models - the length and width gradient for the medium-scale distribution and the aggregation factor $k$ of the negative binomial distribution for the small-scale distribution - was investigated by sensitivity analysis. Pa-

tion probability of a focus than were the length and width gradient parameters. Several existing versions of the statutory sampling method used in the Netherlands were tested for their performance on a standard infestation focus with a central population density of 50 cysts per $\mathrm{kg}$ of soil, which is small enough to use resistant potato cultivars as a control measure without noticeable yield reductions in a 1:3 year cropping frequency with potato. These methods did not perform with the desired average detection probability, set at $90 \%$; therefore, SAMPLE was used to develop several new sampling methods for focus detection. SAMPLE is a tool to develop sampling methods on demand for every possible combination of characteristics required for use by seed and ware potato growers (recommendations for optimum control measures leading to maximum returns and integrated pest management) and by governments (legislation, quarantine, and export protection).
\end{abstract} rameter $k$ proved to be less important when calculating the average detec-
In the 1980 s, $60 \%$ of the total volume of pesticides used in the Netherlands consisted of soil disinfectants for the control of potato cyst nematodes (Globodera rostochiensis and G. pallida). Approximately half of this volume was used for soil fumigation in seed and ware potato areas, located mostly on heavy marine clay soils. Been and Schomaker $(3,6)$ conducted field trials with 1,3-dichloropropene on these soils to investigate the efficiency of soil fumigation and reported average mortalities of $60 \%$ in the upper 25 to $30 \mathrm{~cm}$ of the tilth. However, potato roots and cysts were found down to a depth of $80 \mathrm{~cm}$ (6). The area of the infestations was small compared to the area commonly treated with a fumigant. As a result, more than $90 \%$ of the active compound was wasted on uninfested soils. Large numbers of fields in these areas were treated with fumigants without the demonstrated presence of potato cyst nematodes. The fields were treated as a result of government regulation or as a prevention of an eventual detection of potato cyst nematodes by statutory soil sampling.

To reduce this high, ineffective, and, in most cases, unnecessary input of soil fumigants, sampling methods are needed to detect infestation foci, with a high detection probability, when population densities are low in order to help farmers make decisions on the nature of the control measures required for optimal economic returns. Therefore, knowledge of both the medium-scale (shape and size of foci) and small-scale distribution (within square meters) of potato cyst nematodes was combined in a simulation model to evaluate existing sampling methods and to develop new ones if necessary. A simulation program, SAMPLE, was developed to automate development and testing of sampling methods for detection of infestation foci.

Corresponding author: T. H. Been; E-mail address: t.h.been@plant.wag-ur.nl

Publication no. P-2000-0420-01R

(c) 2000 The American Phytopathological Society

\section{THEORY AND APPROACHES}

Spatial distribution models. The spatial distribution of potato cyst nematodes in the field is not uniform. Fields are free of potato cyst nematodes until an initial infestation occurs. Localized populations will increase every year in which potatoes are grown and cluster at the location where plants have grown, leading to a hot spot or focus (20). Redistribution of nematodes in the soil depends on farming practices, mainly the use of machinery, that cause the growth of the primary focus and the appearance of secondary foci elsewhere in the field. A large-scale, medium-scale, and smallscale distribution can be distinguished. The large-scale distribution refers to a whole field and its number of foci. The medium-scale distribution pattern refers to the size and shape of a focus as a result of farming practices. The small-scale distribution of potato cyst nematodes is the result of multiplication on the roots of evenly spaced potato plants and local effects of redistribution; the result can be described by a probability density function.

Schomaker and Been (14) developed a simple exponential model describing the general shape of a focus based on the analysis of 39 infestation foci, mapped in square-meter units, in various cropping areas of the Netherlands. The general shape of a focus is described by

$$
E[P(x, y)]=P(0,0) \cdot l^{|x|} \cdot w^{|y|}
$$

in which $E[P(x, y)]=$ the expected population density at a certain position with length coordinate $x$ and width coordinate $y$. Table 1 gives further explanations of the symbols. With this model, the expected population density at any location in a focus can be calculated given a certain central population density, $P(0,0)$ and the values of the length gradient parameter $(l)$ and the width gradient 
parameter $(w)$. These parameter values proved to be the same in all cropping areas (14), so that any sampling method for detection will have the same performance throughout the Netherlands.

Cyst counts, estimated by $P(x, y)$, in samples from a small area of about $1 \mathrm{~m}^{2}$ in a focus with coordinates $x$ and $y$ are assumed to follow a negative binomial distribution (16). This distribution and its fitting to biological data is extensively described by many workers including Bliss and Fisher (9). Considering available data from the literature (16) and $k$ values calculated from more than 40 foci and from numerous small-scale distribution patterns (T. H. Been and C. H. Schomaker, unpublished data), an operational value resembling a 'common $k$ ' (10), denoted as $k^{\prime}$, of 70 was established for bulk samples of $1.5 \mathrm{~kg}$ (80 core samples of approximately $20 \mathrm{~g}$ ) originating from $1 \mathrm{~m}^{2}$. The aggregation factor used in the calculations, $k^{\prime \prime}$, is proportional to the (core) sample size taken from that square meter (16).

The probability of detection within a square meter can be defined as the probability of extracting one or more cysts from this area or as 1 minus the probability of finding no cysts at all. The negative binomial distribution function is described by

$$
\operatorname{Pr}[P(x, y)=\alpha]=\left(\begin{array}{c}
\alpha+k-1 \\
k-1
\end{array}\right) \cdot\left\{\frac{E[P(x, y)]}{E[P(x, y)]+k}\right\}^{\alpha} \cdot\left\{\frac{k}{E[P(x, y)]+k}\right\}^{k}
$$

in which Pr indicates the probability of finding a certain number $(\alpha)$ of cysts and $\alpha$ is a integer $\geq 0$. This function can be simplified to equation 3 when $\alpha=0$.

$$
\operatorname{Pr}[P(x, y)=0]=\left\{\frac{k}{E[P(x, y)]+k}\right\}^{k}
$$

The combined use of equations 1 and 3 allows one to calculate the probability of detection when applying a certain sampling method, defined by grid pattern and core sample size, on the one hand, and focus size, defined by the central population density and the values of the length and width gradient parameters, on the other hand.

Simulation model. Terms used in this paper are defined in Table 1 and input parameters required for the simulation program are listed in Table 2.

The finite focus. The exponential model according to equation 1 is infinite, so that population densities will decrease asymptotically toward 0 in all directions. In real life, a focus is limited in size and, therefore, focus dimensions have to be established for use in the calculations. Two different methods are possible, the probability model and the density model. The first method sets a limit to the focus when the probability of detecting no cysts at all in the volume of soil collected by a core sample will exceed a set value according to equation 3 (e.g., $P_{0} \geq 0.99$ ). The second method limits the area of the focus to that area in which the population density is above a set value (e.g., 1 cyst per $\mathrm{kg}$ of soil). Both methods were tested.

The probability model is elegant, but it has some severe drawbacks. When the core sample size changes, detection probabilities will change and, by definition, the size of the focus will change. In an iteration process, close to the desired average detection probability, optimization can fail. In addition, the size of a focus can grow disproportionately by increasing the core sample size to extreme values. Considering these drawbacks, the probability model was discarded in favor of the density model.

Valid sampling grid points. The first step of any calculation will be to match the size of the sampling grid - the number of grid points that will actually be considered in the calculation of probabilitieswith the size of the focus under investigation. Starting with the central population density of the defined focus and stepping along both axes (length and width), using as increment values the grid

\begin{tabular}{|c|c|}
\hline Term & Definition \\
\hline \multicolumn{2}{|l|}{ Sampling grid } \\
\hline Grid point & Location where a core sample will be taken \\
\hline Grid quadrat & Area between four grid points placed in a rectangle; also area represented by one grid point in a rectangular grid \\
\hline Grid quadrat length & Distance between two grid points in the direction of cultivation \\
\hline Grid quadrat width & Distance between two grid points perpendicular to the direction of cultivation \\
\hline Grid pattern & Pattern of grid points of a rectangular grid, defined by a combination of grid quadrat length and width \\
\hline Grid quadrat area & Area covered by one core sample in a grid point $=$ grid quadrat length $\cdot$ grid quadrat width \\
\hline Grid position & Position of grid with respect to center of focus \\
\hline \multicolumn{2}{|l|}{ Soil samples } \\
\hline Core sample & Single sample taken with a sampling auger at a certain grid point \\
\hline Bulk sample & Soil sample taken per standard area (square meter, hectare) consisting of several core samples and processed as one sample \\
\hline Field sample & Soil sample taken per standard area (hectare) consisting of several bulk samples that are separately processed \\
\hline Core sample size & Weight of soil collected by one core sample \\
\hline Bulk sample size & Total weight of all core samples to be processed as one bulk sample \\
\hline Field sample size & Total weight of all core samples to be processed as several bulk samples \\
\hline \multicolumn{2}{|l|}{ Detection probability } \\
\hline $\operatorname{Pr}$ & Probability of detecting one or more cysts by collecting one core sample \\
\hline $\operatorname{Pr} f$ & Probability of detecting one or more cysts by collecting all core samples taken within a focus \\
\hline $\operatorname{Pr}{ }_{\text {average }}$ & Average detection probability; average of all detection probabilities per focus for all possible grid positions \\
\hline $\operatorname{Pr} f$ & $\begin{array}{l}\text { Overall detection probability; average of all average detection probabilities for all combinations of the length and width gradient parameters } \\
\text { according to the bivariate normal distribution }\end{array}$ \\
\hline \multicolumn{2}{|l|}{ Equations } \\
\hline Length direction & Direction of cultivation \\
\hline Width direction & Direction perpendicular to the direction of cultivation \\
\hline$E[P(x, y)]$ & $\begin{array}{l}\text { Expected population density at a certain position in the focus with length coordinate } x \text { and width coordinate } y \text { (cysts per kilogram of soil); also, } \\
\text { parameter of the Negative Binomial Distribution }\end{array}$ \\
\hline$P(0,0)$ & Population density in the center of the focus (cysts per kilogram); this position has the predefined length and width coordinates $x=0$ and $y=0$ \\
\hline$l$ & $\begin{array}{l}\text { Length gradient parameter, the ratio of the cyst density at a position with length coordinate } x \text { and that density at a position with length coordinate } \\
x-1\end{array}$ \\
\hline$w$ & Width gradient parameter, the ratio of cyst density at a position with width coordinate $y$ and that density at a position with width coordinate $y-1$ \\
\hline$x$ & Length coordinate of a given position in the focus: the distance in meters between the focus center and that position in length direction \\
\hline$y$ & Width coordinate of a given position in the focus: the distance in meters between the focus center and that position in width direction \\
\hline$k$ & Coefficient of aggregation; parameter of the Negative Binomial Distribution \\
\hline$k^{\prime}$ & Common $k$ according to Bliss and Owen (10) \\
\hline$k^{\prime \prime}$ & Coefficient of aggregation for the core sample size and proportional to the size of the sample used to estimate $k^{\prime}$ \\
\hline
\end{tabular}

TABLE 1. Terms and variables used 
quadrat length and width, the numbers of relevant grid points (those within the finite focus) in both directions, $g x$ and $g y$, will be calculated. In this way, the size of a rectangle $(2 g x+1 \cdot 2 g y+1=n$ grid points) covering the whole focus is calculated. The program only computes probabilities for the calculated area of the focus and, therefore, is not hampered by the size and shape (such as blocks, strips, or squares) of the spatial unit from which the core samples are collected to constitute the bulk sample. In view of the shape of the focus, most grid points at the corners of the calculated rectangle will be below the threshold value of the density model (Fig. 1). The calculated population density at each grid point will be tested against the threshold value, and grid points below the threshold will be disregarded in further calculations.

In every grid point where a core sample is taken, the expected population density is calculated using equation 1 . The probability of finding 0 cysts in a soil sample from a focus as a whole is defined as the product of the outcomes of equation 3 for all core samples taken within the focus. The complement of this product is the detection probability of a focus, $\operatorname{Pr}^{f}$. If $n$ subsamples are taken

$$
\operatorname{Pr}^{f}(P \geq 1)=1-\prod_{i=1}^{n} \operatorname{Pr}\left[P(x, y)_{i}=0\right]
$$

The position of the focal center. The exact position of the focus within the field is unknown; therefore, the sampling grid can overlay a focus in many different ways and a separate detection prob- ability can be related to all of them. Therefore, SAMPLE systematically shifts the grid in both directions using a step size grid (Table 2) and calculates the detection probability of the focus for each new position of the grid. The above-calculated rectangle of valid grid points has its central grid point in the center of the focus; therefore, the sampling grid will be shifted by half of a grid quadrat length and width to the left and upward, respectively, before the actual simulations start. For example, when a sampling grid of 5 by $5 \mathrm{~m}$ is superimposed over a focus with a central population density of 50 cysts per $\mathrm{kg}$ of soil (standard focus), arrows indicate the directions in which the grid will be shifted (Fig. 1). When the sampling grid has been shifted in both directions, using step size, for distances equivalent to grid quadrat length and width, all possible grid positions will have been evaluated and the last sampling grid will be situated half of a grid quadrat length and width to the right and downward, respectively. The model chosen for the shape of the focus is symmetrical over both axes (14); therefore, only one quadrant needs to be evaluated, thus saving nearly $75 \%$ of calculation time.

Finally, a frequency distribution of detection probabilities per focus is obtained over all grid positions. If the grid was shifted $N$ times, the average detection probability is

$$
\operatorname{Pr}_{\text {average }}^{f}(P \geq 1)=\frac{\sum_{i=1}^{N} \operatorname{Pr}_{i}^{f}(P \geq 1)}{N}
$$

TABLE 2. Required variables for program input (SAMPLE) and their origin or description

Variable

Central population density Length gradient parameter Width gradient parameter Grid quadrat length Grid quadrat width

Core sample size

Step size grid

Aggregation factor

Threshold value
Origin or description

$P(0,0)$ from equation 1 in cysts per kilogram of soil

$l$ from equation 1

$w$ from equation 1

Dimension of the sampling grid in the direction of cultivation (e.g., $5 \mathrm{~m}$ )

Dimension of the sampling grid in the direction perpendicular to the direction of cultivation (e.g., $5 \mathrm{~m}$ )

Weight of soil collected by one core sample $(\mathrm{g})$

Distance in centimeters used to shift the sampling grid in $l$ or $w$ direction, or both (default, $0.1 \mathrm{~m}$ )

$k^{\prime}$ for $1.5 \mathrm{~kg}$ of soil

Value used to limit focus dimension in length and width direction; $P_{0}>0.99$ (probability model), 1 cyst per kg of soil (density model)

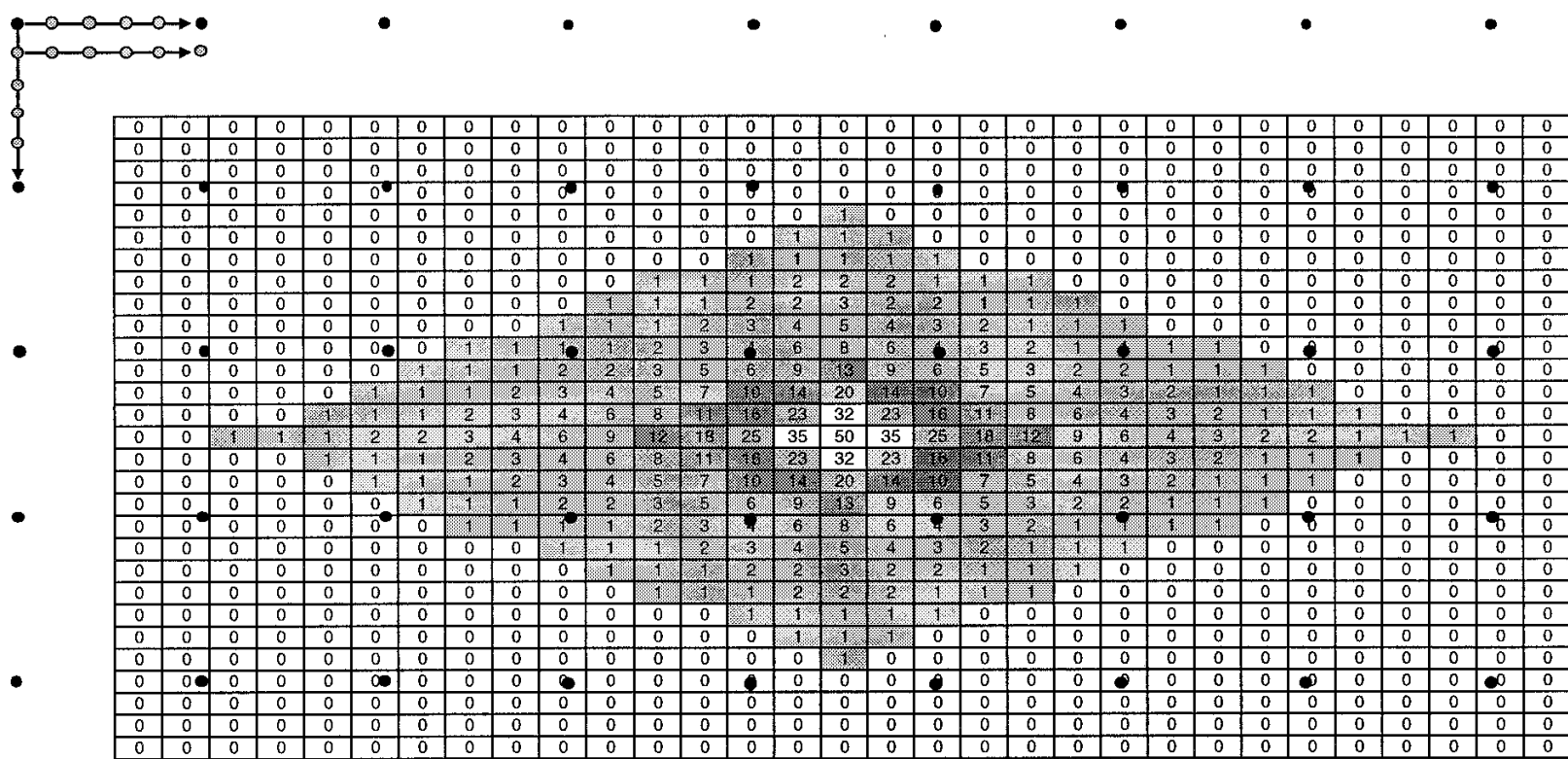

Fig. 1. Map of a focus with a central population density of 50 cysts per $\mathrm{kg}$ of soil and length and width gradient parameters according to the $10 \%$ lower percentile of the bivariate normal distribution (standard focus). Population densities (cysts per kilogram) per square meter (1.33 by $0.75 \mathrm{~m}$ ) calculated according to equation 1 . A grid pattern of 5 by $5 \mathrm{~m}$ is superimposed. Arrows indicate the shift of the grid in both directions to calculate the average detection probability and its variance. The shift distance (called step size) of the grid can be set to any value from $1 \mathrm{~cm}$ upward (default, $10 \mathrm{~cm}$ ). 
Schomaker and Been (14), having analyzed foci scattered over many cropping areas in the Netherlands, found that both the length and width gradient parameters are normally distributed. As a result, the frequency of occurrence of any combination of both gradient parameters in the field can be described by a bivariate normal distribution. Using this distribution, an overall detection probability for the standard focus can be calculated. The overall detection probability is defined as the sum of the products of the average detection probability of that focus for each possible combination of the length and width gradient parameters and the probability of occurrence of that combination. If there are $n_{l}$ possible values for the length gradient parameter and $m_{w}$ possible values for the width gradient parameter and each combination of the length and width gradient parameters has the frequency of occurrence of freq $_{i, j}$, then

$$
\operatorname{Pr}_{\text {overall }}^{f}=\frac{\sum_{i=1}^{n_{l}} \sum_{j=1}^{m_{w}}\left(\operatorname{Pr}_{\text {average }}^{f} \cdot \text { freq }_{i, j}\right)}{\left(n_{l} \cdot m_{w}\right)}
$$

Defining a standard focus. Before sampling methods for detection can be evaluated or new methods are developed, a standard focus that one wants to detect with a set probability must be chosen. Three requirements can be postulated. First, the level of infestation at detection should be so low that farmers can take control measures as soon as possible, but with at least one crop rotation period of potatoes before the infestation becomes visible in the next potato crop. Second, the population densities in the center of the focus should not exceed the population threshold for damage at the time of planting a new potato crop. Resistant potato cultivars, which differ from susceptible ones only in their quality as a host, will then suffer hardly any growth reduction. A direct result will be no visible infestation in the crop. Third, detection of

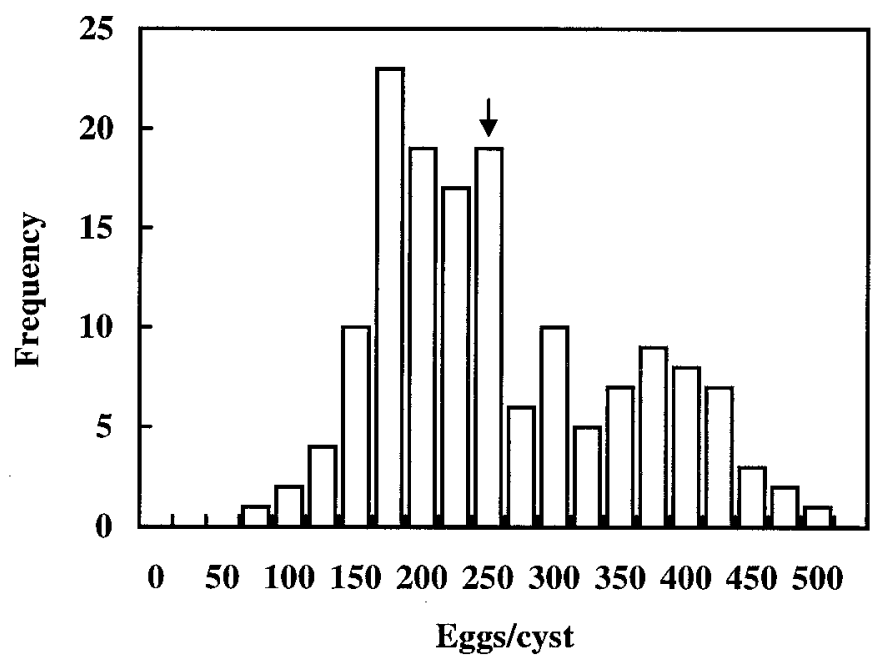

Fig. 2. Frequency distribution (count units) of eggs per cyst per batch of cysts from $1-\mathrm{m}^{2}$ samples with population densities between 30 and 70 cysts per $\mathrm{kg}$ of soil originating from nine foci. Arrow indicates selected value. a focus should occur early, so that the probability of secondary foci and point infestations caused by infested clods of soil adhering to and transported by machinery (12) would be low.

To establish the average number of eggs per cyst immediately after the susceptible potato cultivar Bintje is grown, the contents of batches of cysts, originating from $1-\mathrm{m}^{2}$ samples from nine foci, were determined. Assuming that a number of 50 cysts per $\mathrm{kg}$ of soil should approximately contain the number of eggs to approach the damage threshold ( $T=2$ eggs per $g$ of soil at planting) (15), population densities (eggs per gram of soil) of batches of cysts at densities between 30 to 70 cysts per $\mathrm{kg}$ of soil were analyzed. The resulting frequency distribution of eggs per cyst was slightly skewed (Fig. 2). An average of 248 eggs per cyst was calculated, and a value of 250 eggs per cyst was used for further calculations. Two to three years of nonhost crops will follow in which the population density decreases. This decline, investigated by Den Ouden (11), is averaged at $50 \%$ per year in the first year after a potato crop and $35 \%$ per year in subsequent years (8).

With the information presented above, a focus with a central population density of 50 cysts per kg of soil (approximately 12.5 eggs per $g$ of soil) was calculated as being a suitable standard focus. A two-dimensional image of the standard focus, which apart from its central population density is defined by length and width gradient parameters according to the $10 \%$ lower percentile of their frequency distribution (13), is shown in Figure 1. Population densities would be expected to decrease to 4.1 and 2.6 eggs per $g$ of soil in 1:3 and 1:4 cropping frequency of potatoes, respectively. These densities are only slightly above the tolerance limit $(T)$ of 2 eggs per $g$ of soil (15). No yield reductions will occur and the infestation will not be visible in the crop. For the accuracy of detection of the standard focus, a $90 \%$ probability was arbitrarily chosen as a minimum requirement for performance of a sampling method.

Analyses. Sensitivity analyses were carried out for various parameters of equations 1 and 3 , using the statutory soil sampling methods used in the Netherlands (Table 3) and the above-defined standard focus to determine the importance of individual parameters on the average detection probability. The effect of different dimensions of the grid pattern on the size of the core and field sample required to detect the standard focus with an average detection probability of $90 \%$ was investigated. Finally, SAMPLE was used to develop several new sampling methods for seed and ware potato growers and to evaluate the performance of both the statutory and the new sampling methods over the range of possible focus sizes as established by Schomaker and Been (14).

\section{RESULTS}

Sensitivity analysis. The sensitivity analyses (Fig. 3A and B) show that the length and width gradient parameters both strongly influence the average detection probability. This influence is stronger the greater the bulk sample, because the increase of the bulk sample from 200 to $600 \mathrm{ml}$ increases the average detection probability by a factor varying from 2 to 4 . Schomaker and Been (13) decided to set the length and width gradient parameters (data originating only

TABLE 3. Characteristics of several Dutch versions of the statutory soil sampling method ${ }^{\mathrm{a}}$

\begin{tabular}{|c|c|c|c|c|c|}
\hline \multirow[b]{2}{*}{ Sampling agency } & \multicolumn{2}{|c|}{ Core } & \multicolumn{2}{|c|}{ Grid quadrat } & \multirow{2}{*}{$\begin{array}{l}\text { Bulk sample size } \\
\text { (ml/0.33 ha) }\end{array}$} \\
\hline & Number $(n)^{\mathrm{b}}$ & Size $(\mathrm{ml})$ & Length $(\mathrm{cm})$ & Width $(\mathrm{cm})$ & \\
\hline Oosterbeek & 60 & $3.33^{\mathrm{c}}$ & 750 & 750 & 200 \\
\hline NAK Delta Nederland & 60 & 3.33 & 400 & 1,200 & 200 \\
\hline NAK Assen & 60 & 3.33 & 500 & 1,000 & 200 \\
\hline NAK Emmeloord & 120 & $5.00^{\mathrm{d}}$ & 250 & 1,100 & 600 \\
\hline NAK Friesland/Groningen & 120 & 5.00 & 500 & 500 & 600 \\
\hline
\end{tabular}

a The method of the Laboratory for Soil and Crop Testing (Oosterbeek) is in accordance with the regulations issued by the Dutch Plant Protection Service.

b Number of cores per 0.33 ha.

collected with a kind of spoon.

${ }^{\mathrm{d}}$ Collected with a 5-cm-long auger; diameter approximately $1 \mathrm{~cm}$. 
from one cropping area) to the $10 \%$ lower percentile of their distributions when running simulations: this value was 0.76 and 0.60 for the length gradient and width gradient parameters, respectively. When these values are used for the calculation of a certain average detection probability, $90 \%$ of the foci will have these gradient parameters or larger ones and, therewith, an average detection probability equal to or larger than the chosen one.

Sensitivity analysis of the effect of variation in $k$ (Fig. 3C) on the average detection probability revealed that the latter hardly changed when the actual $k$ (defined for samples of $1.5 \mathrm{~kg}$ of soil per $\mathrm{m}^{2}$, and estimated in a common $k\left[k^{\prime}\right]$ as being 70) increased from 40 to 100. The impact of $k$ on the detection probability is low because the aggregation factor belonging to a core sample depends on its size, $k^{\prime \prime}$, being proportional to the size of the sample used to estimate the common $k$. Core sample sizes for statutory soil sampling are generally only several grams or decigrams (Table 3) (17); therefore, $k^{\prime \prime}$ for the core sample size will almost always be below 1 . This implies considerable aggregation that hardly changes when the $k$ value for $1.5-\mathrm{kg}$ bulk samples is increased. It is concluded that, for the current purpose, some variation of $k$ can be accepted so that a common $k, k^{\prime}$, can be used as described by Seinhorst (16).

Statutory sampling methods. Several Dutch sampling methods, defined by grid pattern and core sample size (Table 3), were evaluated for their efficiency to detect the standard focus (Table 4). In the 1990s, five methods were used in the Netherlands. The method used by the Laboratory for Soil and Crop Testing (Oosterbeek) is the statutory sampling method according to the regulations issued by the Dutch Plant Protection Service. The Dutch General Inspection Service for Agricultural Seeds and Seed Potatoes (NAK) Delta Nederland and NAK Assen only changed the grid pattern to reduce the walking distance for the soil sampler and thus the costs. NAK Emmeloord and NAK Friesland-Groningen doubted the efficiency of collecting only $200 \mathrm{ml}$ per 0.33 ha and tripled the bulk sample size. Both agencies covered prime seed potato areas in the Netherlands and wanted to contribute to keeping these areas free from potato cyst nematodes. Most other statutory sampling methods within the European Community are derived from the Dutch methods, although there is a tendency to sample larger areas. For the Dutch methods, the average detection probability of the standard focus was calculated (Table 4, column 3). The 200-ml sampling methods detect the standard focus only with an average detection probability of about $6 \%$, whereas the $600-\mathrm{ml}$ methods yield average detection probabilities of about $17 \%$.

The required number of cysts per kilogram in the center of the focus at which detection will occur with an average detection probability of $90 \%$ using the respective methods was determined (Table 4, column 4). The 200-ml methods require foci with extremely high central population densities to detect with this probability, much higher population densities than those actually found under field conditions. The highest densities ever found were 2,500 to 3,500 cysts per kg, whereas Schomaker and Been (14), in a survey of almost 100 infested fields, did not detect central population densities higher than 1,500 cysts per kg. Two sample sizes were calculated, both re- quired in the detection of the standard focus with $90 \%$ average detection probability (the core sample size and the associated field sample size per $0.33 \mathrm{ha}$ ). A surprising result was that two methods, NAK Emmeloord and NAK Friesland-Groningen, which collect the
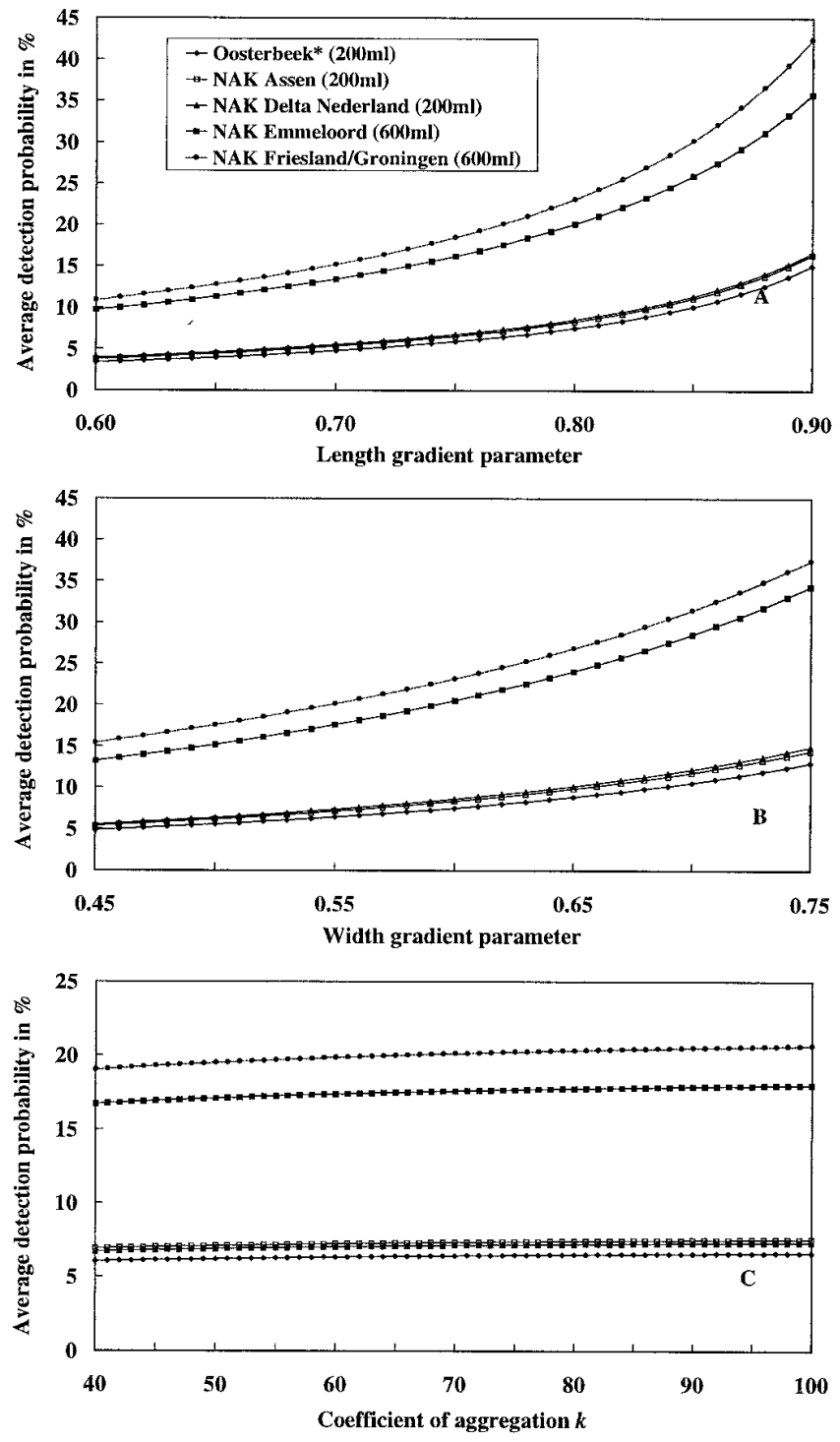

Fig. 3. Sensitivity analysis of the effect of $\mathbf{A}$, the length gradient parameter and $\mathbf{B}$, width gradient parameter in the exponential model (medium-scale distribution, equation 1) on the average detection probability of a standard focus. C, Sensitivity analysis of the effect of the coefficient of aggregation $k$ (negative binomial distribution, equation 3) on the average detection probability of a standard focus. Focus: central population density of 50 cysts per $\mathrm{kg}$, $l=0.77, w=0.55(14), k=70$. Sampling method: grid patterns, core sample sizes, and bulk sample sizes as described in Table 3.

TABLE 4. Performance of several Dutch versions of the statutory soil sampling method

\begin{tabular}{|c|c|c|c|c|c|c|}
\hline \multirow[b]{2}{*}{ Sampling agency } & \multirow{2}{*}{$\begin{array}{l}\text { Bulk sample size } \\
\text { (ml/0.33 ha) }\end{array}$} & \multirow{2}{*}{$\begin{array}{l}\text { Average detection } \\
\text { probability }(\%)^{\mathrm{a}}\end{array}$} & \multirow{2}{*}{$\begin{array}{l}90 \% \text { Average detction } \\
\text { probability }^{\mathrm{b}}(\text { cysts } / \mathrm{kg} \text { ) }\end{array}$} & \multicolumn{2}{|c|}{ Required sample size ${ }^{\mathrm{c}}$} & \multirow{2}{*}{$\begin{array}{l}\text { Overall detection probability } \\
\text { of standard focus }(\%)^{\mathrm{d}}\end{array}$} \\
\hline & & & & Core $(\mathrm{g})$ & Field (kg/0.33 ha) & \\
\hline Oosterbeek & 200 & 5.8 & 9,200 & 172 & 10.0 & 12.2 \\
\hline NAK Delta Nederland & 200 & 6.6 & 8,300 & 468 & 32.2 & 13.8 \\
\hline NAK Emmeloord & 600 & 15.9 & 1,650 & 176 & 21.2 & 30.8 \\
\hline NAK Friesland/Groningen & 600 & 18.4 & 1,000 & 61 & 8.0 & 34.6 \\
\hline
\end{tabular}

${ }^{a}$ Average detection probability according to the $10 \%$ lower percentile of the length and width gradient parameters $(0.77$ and 0.55$)$ according to Schomaker and Been (14).

${ }^{\mathrm{b}}$ Probability at a central population density.

c Required sample size for $90 \%$ average detection probability of standard focus.

${ }^{\mathrm{d}}$ Overall detection probability according to the bivariate normal distribution of the length and width gradient parameters. 
same bulk sample size (600 g of soil) and have almost the same average detection probability for the standard focus (about 17\%), required core sample sizes and bulk sample sizes differing by a factor of three to detect the standard focus at the set probability. The explanation for this difference lies in the grid patterns. The NAK Friesland-Groningen grid pattern of 5 by $5 \mathrm{~m}$ is more favorable than the 2.5 by $11-\mathrm{m}$ grid pattern of NAK Emmeloord, the latter being incongruent with the shape of the focus.

The overall detection probability was determined (Table 4). It is evident that, although the overall detection probabilities are higher than the average detection probabilities based on the $10 \%$ lower percentile, none of the statutory soil sampling methods qualifies for the required $90 \%$ detection level.

Efficiency of sampling methods. The dimensions of the grid pattern obviously affect the field sample size necessary to obtain a certain average detection probability; therefore, SAMPLE was used to establish the optimum grid pattern. The sample size required for a $90 \%$ detection probability was calculated for a variety of grid patterns, from 2 by $2 \mathrm{~m}$ to 11 by $11 \mathrm{~m}$, and for several combinations of the length and width gradient parameters. The wider the grid pattern used, the larger the soil sample needed to detect the standard focus with $90 \%$ average detection probability, and the relation was by no means linear (Fig. 4). Further, an increase in grid quadrant length was less sensitive than the same increase in grid quadrant width. The effect became less noticeable when higher values for the length and width gradient parameters were used (foci covering a larger area). Thus, the field sample size required to
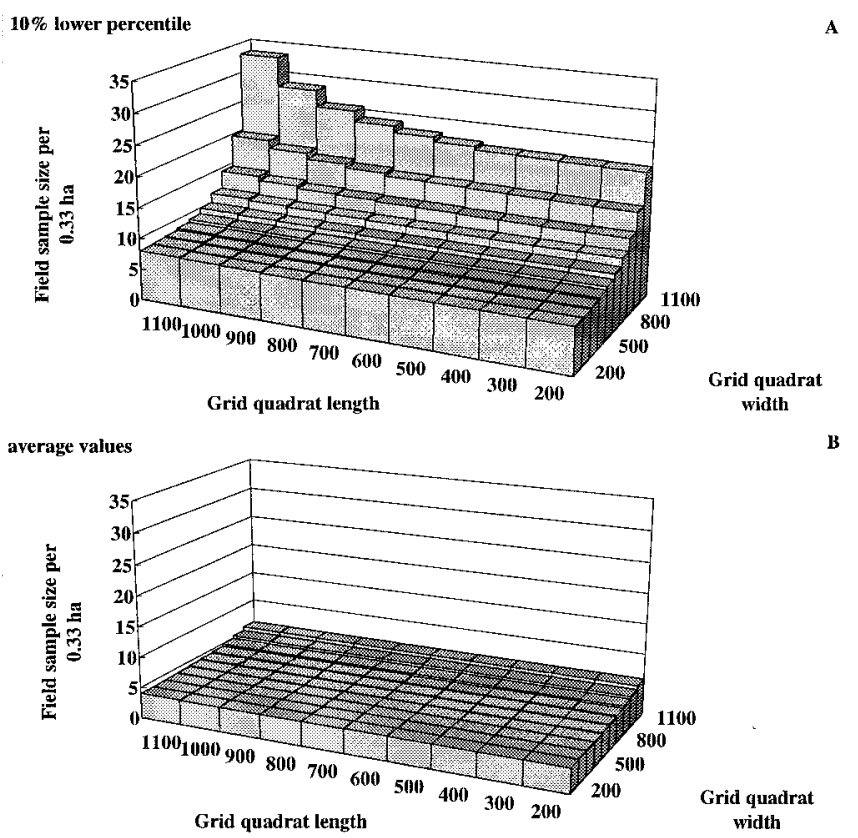

B

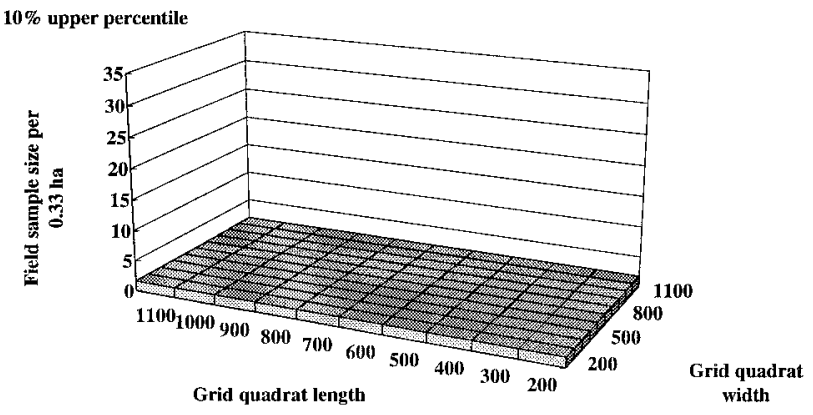

Fig. 4. Sensitivity analyses for grid patterns. The field sample size in kilograms per 0.33 hectare required to detect the standard focus with an average detection probability of $90 \%$ was calculated for grid patterns varying from 2 by 2 to 11 by $11 \mathrm{~m}$ in size using the A, $10 \%$ lower; B, mean; and C, $10 \%$ upper percentile of the bivariate normal distribution of the length and width gradient parameters. detect the standard focus with an average detection probability of $90 \%$ varied from $6.7 \mathrm{~kg}$ for a grid pattern of 2 by $2 \mathrm{~m}$ to $33 \mathrm{~kg}$ for a grid pattern of 12 by $12 \mathrm{~m}$ when the lower $10 \%$ percentile of the bivariate distribution of the length and width gradient parameters was used ( $l=0.77, w=0.55$ ) (Fig. $4 \mathrm{~A}$ ), from 3.9 to $5.9 \mathrm{~kg}$ when the average values were used $(l=0.83, w=0.64)$ (Fig. 4B), and from 1.6 to $1.7 \mathrm{~kg}$ when the upper $10 \%$ percentile was used $(l=$ $0.91, w=0.76$ ) (Fig. 4C).

Another consequence of differences in grid patterns was demonstrated by comparing the frequency distributions (number of occurrences) of detection probabilities of the grid patterns ( 2 by 2 and 11 by $11 \mathrm{~m}$ ) for the same three combinations of the length and width gradient parameters used for Figure 4 (Fig. 5). Although sample sizes were adjusted so that, for both grid patterns, the standard focus was detected with an average detection probability of $90 \%$, the variance of the detection probabilities for various grid positions was much smaller for the 2 by $2-m$ grid pattern than for the 11 by $11-\mathrm{m}$ grid pattern. For the individual farmer who samples his field only once and, therefore, draws only once from this frequency distribution, a sampling method with a closely spaced grid pattern is more reliable. The frequency distribution of the 11 by $11-\mathrm{m}$ grid pattern in Figure 5A (for the lower 10\% percentile) displays a large number of zero probability detections. In these cases, grid positions occur without any grid point touching the focus. As a result, the core sample size has to be drastically increased for those grid
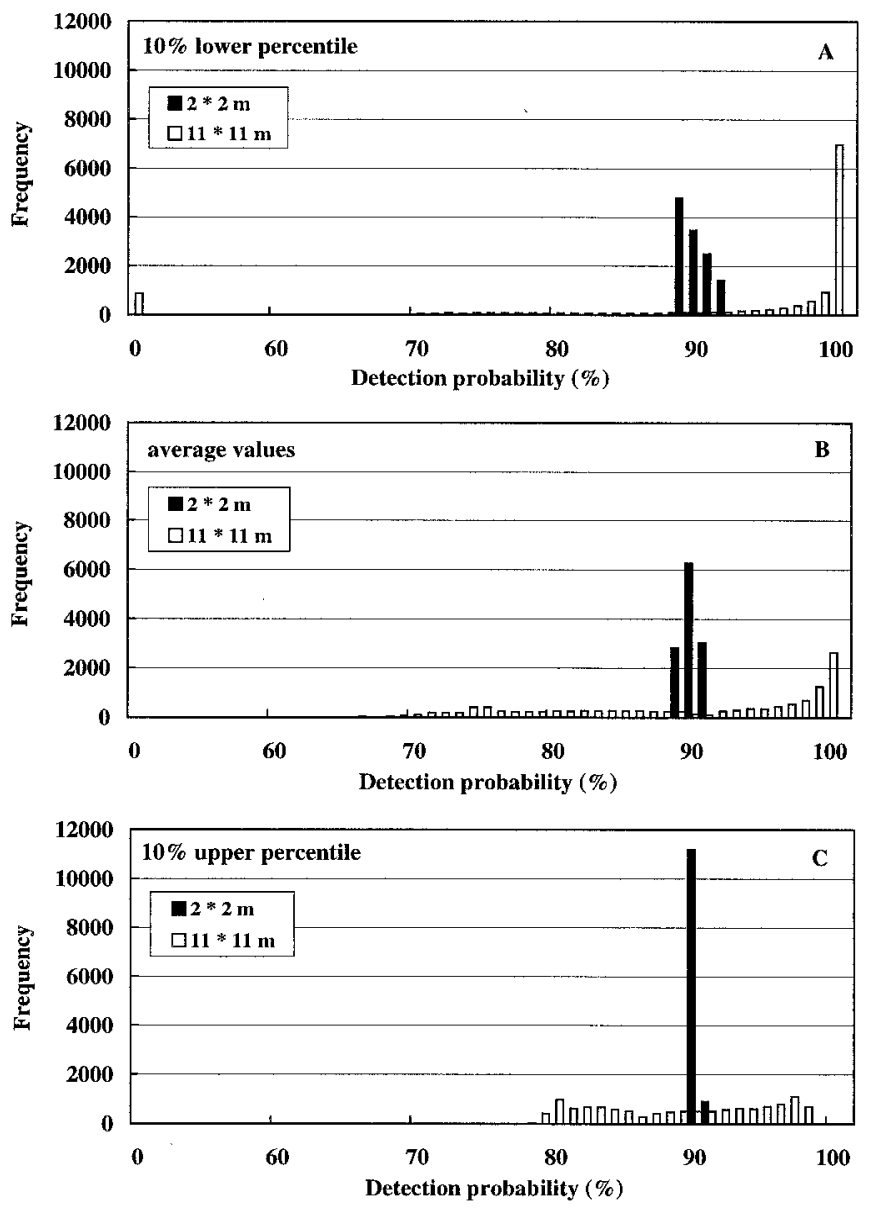

Fig. 5. Comparison of the frequency distributions of detection probabilities for grid patterns of 2 by 2 ( $\square$ ) and 11 by $11 \mathrm{~m}$ (ם) (length by width) at the $\mathbf{A}$, $10 \%$ lower; B, mean; and C, $10 \%$ upper percentile of the bivariate normal distribution of the length and width gradient parameters. The two grid patterns produce the same average detection probability $(90 \%)$ for the standard focus (using different core sample sizes), but they differ in their variance. Note: A grid quadrat of 11 by $11 \mathrm{~m}$ and step size grid of $10 \mathrm{~cm}$ for the sampling grid yields $110 \times 110=12,100$ simulated sampling results; the frequencies of the 2 by $2-\mathrm{m}$ grid were converted to the same number for comparison. 
positions that do touch the focus in order to obtain the desired average of $90 \%$ detection probability. The field sample size has to be increased by $13 \mathrm{~kg}$ when stepping from the 11 by $10-\mathrm{m}$ grid pattern to the 11 by $11-\mathrm{m}$ grid pattern. An 11 by $12-\mathrm{m}$ grid pattern has $25 \%$ of the grid positions with zero probability of detection, and an average detection probability of $90 \%$ is impossible.

Optimization of sampling methods. The comparison of the statutory sampling methods (Table 4) indicated that new soil sampling methods for detection had to be developed. A prototype version, based on a limited data set originating from the province Flevoland using a grid pattern of 5 by $5 \mathrm{~m}$, was introduced in the Netherlands (13) in 1989 (Table 5). According to Schomaker and Been (14), who analyzed a more comprehensive data set, the values of the $10 \%$ lower percentiles of the length and width gradient parameters, which were used to develop the prototype method, had to be adapted. As a result, the core sample size had to be increased from 53 to $61 \mathrm{~g}$, which yielded a new field sample size of $24.1 \mathrm{~kg}$, to ensure the desired average detection probability of $90 \%$ (adapted method 1). Using the bivariate distribution of the two parameters, a method could be developed that was optimized to detect an average of $90 \%$ of all possible combinations of these parameters (adapted method 2). A substantial reduction in core and field sample sizes was the result.

Because of the large amount of soil that had to be collected, bulk samples of areas smaller than the standard 0.33 ha were collected and processed. As secondary infestations and point infestations occurred upward and downward in the direction of cultivation, the almost square area from which to collect a bulk sample was replaced by an elongated rectangular area or strip. On average, strips were $300 \mathrm{~m}$ long, covering the complete field in the direction of cultivation and as wide as the grid quadrat width. The prototype sampling method utilized a grid pattern of 5 by $5 \mathrm{~m}$. By combining all core samples over areas $5 \mathrm{~m}$ wide and $300 \mathrm{~m}$ long into one bulk sample, almost seven bulk samples per ha were collected. This grid pattern was inconvenient because most agricultural machinery has a working width measured in multiples of $3 \mathrm{~m}$. As a result, when growing a resistant cultivar as a control measure, the area in the width of the field generally did not cover the same width as the sampled and infested area. Unfavorable dimensions pose problems with the registration systems currently under development, which need a standard width to store information. Consequently, the final sampling method for detection of foci (adapted method 3) was based on a grid pattern $5 \mathrm{~m}$ long by $6 \mathrm{~m}$ wide.

The statutory soil sampling method, with a grid pattern of 7.5 by $7.5 \mathrm{~m}$ and a core sample size of $3.3 \mathrm{~g}$ (bulk sample size of $200 \mathrm{~g}$ per $0.33 \mathrm{ha}$ ) is still used because of European and Mediterranean Plant Protection Organization (EPPO) regulations; therefore, it was compared with the prototype sampling method (13) and the new method (adapted method 3) for two aspects: (i) the size of the focus detected with a $90 \%$ overall detection probability (Fig. 6), and (ii) their overall detection probabilities for foci of different central population densities (Fig. 7). Given an overall detection probability of $90 \%$, the new sampling method detects foci with central densities 60 times smaller than does the statutory soil sampling method. Although the new method requires $7 \mathrm{~kg}$ of soil less to be collected per hectare compared with the prototype method, its performance over the calculated range of infestation foci differs only marginally. The new method detects foci with a central density of 200 cysts per kg of soil and higher with high (approximating 100\%) average probability, while the prototype method performs at this level starting with 100 cysts per $\mathrm{kg}$ of soil.

The prototype sampling method and all adapted methods focused on seed potato growers with narrow cropping frequencies. This resulted in sampling methods that required large soil samples. Possibilities were explored to reduce the size of the bulk sample when ware potatoes are grown (Table 6). The less frequently ware potatoes are grown, the bigger the focus may develop before detection by the sampling method is required, because a longer period of nonhost years will follow. For every extra nonhost crop season, the acceptable central population density of the focus to be detected may increase by the average reduction of population densities during that extra year (35\%). As a result, a smaller amount of soil has to be collected. Another possibility would be to change the average detection probability required to detect an infestation focus and to calculate the field sample size needed to be collected for each of these foci, thereby presenting the possibility to choose both the size of the focus to be detected and the average probability of detection. Evidently, the larger the infestation focus, the smaller the required field sample size (Fig. 8). However, the effect of reducing the average detection probability from 90 to 80 or $70 \%$ reduces the required soil sample drastically when small infestation foci have to be detected.

\section{DISCUSSION}

The soil sampling methods compared in this study (Table 3) are applied for different purposes in the Netherlands. They are used as statutory sampling methods by the government to protect the export of seed potatoes or are part of regulations on quarantine and control of potato cyst nematodes. Farmers want sampling methods for optimum control measures that lead to maximum returns, preferably before detection occurs by statutory soil sampling methods. In the Multi-Year Crop Protection Plan of the Dutch government (1), monitoring by soil sampling is advocated as a method to restrict the input of nematicides by avoiding preventive soil fumigation and applying need-based nematicide treatments only. SAMPLE can be used to develop optimum sampling methods for such purposes.

TABLE 6. Sampling methods suitable to farmers growing ware potatoes at different cropping frequencies ${ }^{\mathrm{a}}$

\begin{tabular}{lccc}
\hline \multirow{2}{*}{$\begin{array}{l}\text { Cropping frequency } \\
\text { of potatoes }\end{array}$} & $\begin{array}{c}\text { Central population } \\
\text { density of focus }\end{array}$ & \multicolumn{2}{c}{ Sample size } \\
\cline { 3 - 4 } $1: 3$ & 100 & 21 & Core $(\mathrm{g})$ \\
$1: 4$ & 150 & 15 & Field (kg/0.33 ha) \\
$1: 5$ and higher & 225 & 10 & 1.7 \\
\hline
\end{tabular}

a All methods use a grid pattern of 5 by $6 \mathrm{~m}$ (length by width) and have an overall detection probability of $90 \%$.

b Cysts per kilogram of soil

TABLE 5. Features of several versions of a new sampling method for the detection of potato cyst nematodes

\begin{tabular}{|c|c|c|c|c|c|c|c|c|}
\hline \multirow{2}{*}{$\begin{array}{l}\text { Sampling } \\
\text { method }^{\mathrm{a}}\end{array}$} & \multicolumn{2}{|c|}{ Gradient parameter } & \multicolumn{2}{|c|}{ Grid quadrat } & \multirow{2}{*}{$\begin{array}{l}\text { Core sample } \\
\text { size }(\mathrm{g})\end{array}$} & \multirow{2}{*}{$\begin{array}{l}\text { Field sample size } \\
(\mathrm{kg} / 0.33 \mathrm{ha})\end{array}$} & \multirow{2}{*}{$\begin{array}{l}\text { Bulk sample } \\
\text { size }(\mathrm{kg})\end{array}$} & \multirow{2}{*}{$\begin{array}{c}\text { Overall detection } \\
\text { probability }(\%)\end{array}$} \\
\hline & Length $(l)$ & Width $(w)$ & Length $(\mathrm{cm})$ & Width $(\mathrm{cm})$ & & & & \\
\hline Prototype & 0.76 & 0.60 & 500 & 500 & 53 & 7.0 & 3.0 & 96.4 \\
\hline Adapted 1 & 0.77 & 0.55 & 500 & 500 & 61 & 8.0 & 3.4 & 97.5 \\
\hline Adapted 2 & \multicolumn{2}{|c|}{ Bivariate distribution } & 500 & 500 & 34 & 4.5 & 1.9 & 90.0 \\
\hline Adapted 3 & \multicolumn{2}{|c|}{ Bivariate distribution } & 500 & 600 & 42 & 4.6 & 2.0 & 90.0 \\
\hline
\end{tabular}

a The prototype method has been in use in Dutch agriculture since 1989 (13). Adapted method 1 is an adjustment of the prototype method due to research carried out in all potato cropping areas of the Netherlands (14). Adapted method 2 is the result of applying the bivariate normal distribution (set to $90 \%$ overall detection probability) instead of the $10 \%$ lower percentile of the length and width gradient parameters. Adapted method 3 takes into account the requirement of a basic registration unit $(6 \mathrm{~m})$ compatible with farm operations. 
The results shown in Table 4 justified the development of new improved sampling methods for detection. A favorable grid pattern had to be used to reduce the required bulk sample size. According to the analyses, grid patterns of 2 by $2 \mathrm{~m}$ would be the best of those calculated, and smaller ones probably even better. However, reducing the grid quadrat in size to obtain denser grid patterns only yields low profit in reducing the field sample size and it cannot significantly improve the frequency distribution of detection probabilities, whereas the number of core samples increases prohibitively. A range of grid patterns is acceptable when considering only the field sample size, but a compromise has to be found for two conflicting aims when actual implementation of a sampling scheme is considered: minimizing the sample size and the variance of the detection probability on the one hand and minimizing the time needed to collect and process the samples on the other hand. Schomaker and Been (13) and Been and Schomaker (4) tried to achieve this compromise by utilizing a grid pattern of 5 by $5 \mathrm{~m}$ for their prototype sampling method.

The prototype sampling method was developed specifically for seed potato growers. Although government regulation concerning potato cyst nematodes has drastically changed in the Netherlands, primarily to reduce the input of nematicides, it is still prohibited to grow seed potatoes on infested soils. Farmers, confronted with such a situation, are allowed to grow resistant potato varieties, but only for human consumption or industrial processing. The financial loss in a prime seed potato area, such as the province Flevoland, amounts to 2,600 to 3,800 guilders (about U.S. $\$ 1,400$ to 2,000 ) net per ha
(2), far more than the costs of the new sampling method (about 200 guilders or U.S. $\$ 100$ per ha). The proposed sampling methods detect foci long before the statutory soil sampling method will do so; therefore, farmers will be able to take control measures to reduce the infestation and prevent detection by statutory soil sampling methods. Precise information on the width of the focus is supplied; therefore, the size of the focus can be estimated and customer-designed recommendations for control can be provided (7).

When ware potatoes are grown, almost no regulatory restrictions are applied. No statutory soil sampling is carried out. Instead, the Plant Protection Service performs aerial surveys of potato fields and registers the locations where bare patches or bad growth are visible. Soil samples are taken on the spot, and when the presence of potato cyst nematodes is demonstrated, resistant cultivars have to be grown until subsequent soil sampling proves the field to be free from cysts (meaning that no cysts were found using the statutory sampling method). The use of resistant varieties amounts to a net loss of 600 to 1,800 guilders (about U.S. $\$ 300$ to 950) per ha (2) compared with growing the popular, but susceptible, cultivar Bintje. For a typical bare patch to be spotted from the air, an area of at least $25 \mathrm{~m}^{2}$ of reduced growth is necessary. Any reasonably attentive farmer will spot such an infestation in the preceding potato crop when growth reduction is still small. When rotations of 1:4 or wider are practiced, visible damage in the next potato crop will become harder to notice as a result of redistribution and population decrease. However, the infestation will spread; secondary infestations will occur, and, slowly, the complete field will be

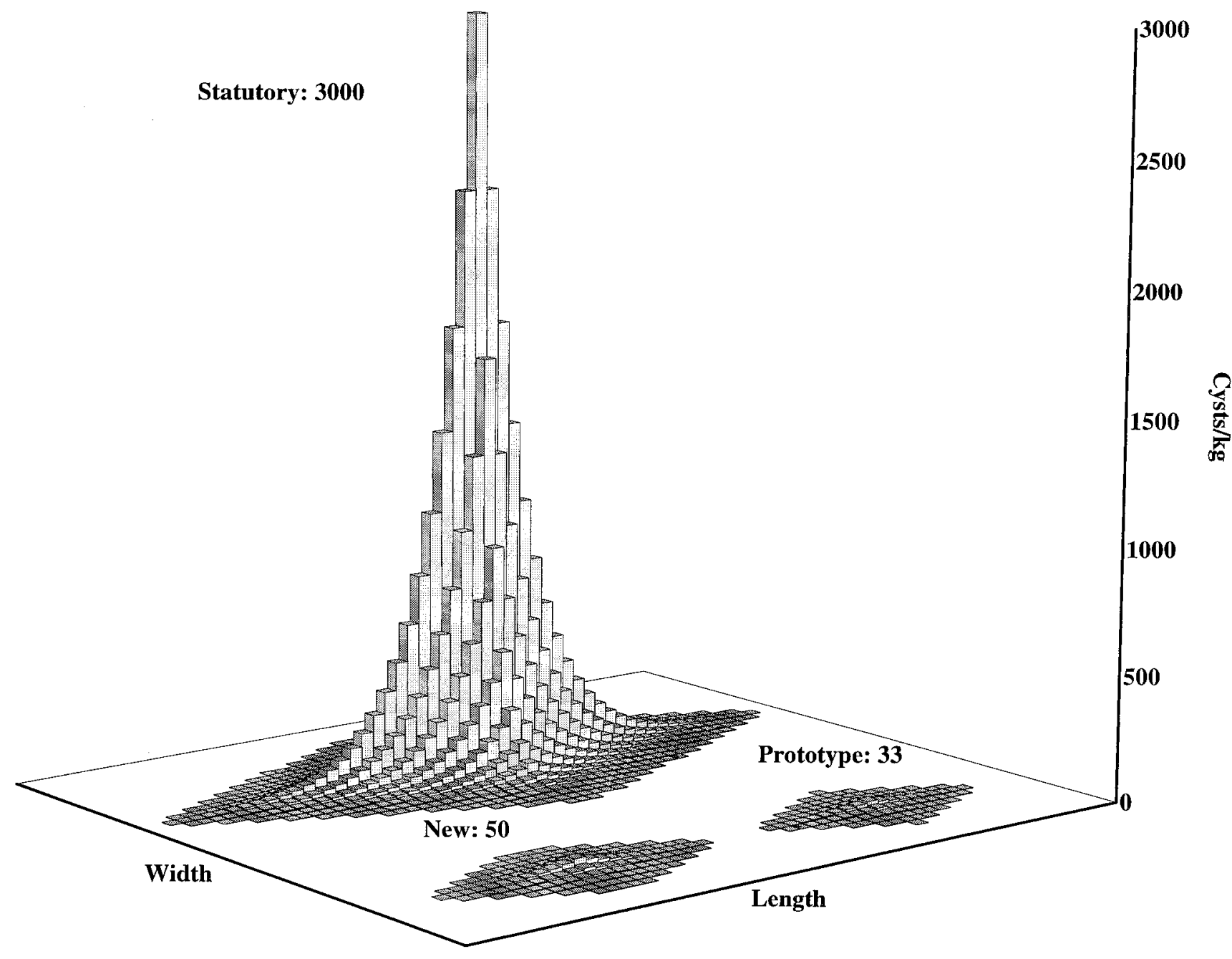

Fig. 6. Comparison of foci detected with a $90 \%$ average detection probability by the statutory, prototype, and new (adapted 3) sampling methods (3,000, 33, and 50 cysts per kg in the center, respectively) at the lower $10 \%$ percentile of the bivariate normal distribution of the length and width gradient parameters. 
contaminated. Been and Schomaker (5) demonstrated the presence of secondary foci in $94 \%$ of the fields sampled. The average area contaminated by the primary focus increases from 370 to $1,150 \mathrm{~m}^{2}$ when $P(0,0)$ increases from 50 to 1,000 cysts per $\mathrm{kg}$ of soil. Most of the infested area contains low population densities of the potato cyst nematode. When a field becomes more or less uniformly infested, densities will build up. At this stage, yield reductions can be suffered without being seen, because comparison with uninfected areas in the same field is not possible. Growing seed potatoes or export crops (e.g., flower bulbs) on these fields, which are only permitted on nematode-free soil, will become impossible. Sampling, therefore, is still required, although not as intensively as for seed potato growers.

An option to establish a rationale for defining sampling methods for ware potato growers is to link the size of the infestation focus to be detected to the cropping frequency. A maximum focus size can be established, above which yield reduction by or spread of potato cyst nematodes is considered too high. The latter criterion is given more emphasis as yield reductions of even large foci (1,500 cysts per $\mathrm{kg}$ of soil in the center) are of no consequence when yield is calculated per hectare (7) but an increasing area will be contaminated. An arbitrary limit was set at 225 cysts per $\mathrm{kg}$ of soil in the center when approximately $700 \mathrm{~m}^{2}$ is contaminated by the primary focus alone and approximately $900 \mathrm{~m}^{2}$ by secondary foci (5). As a result, ware potato farmers can make use of less intensive sampling methods that will be accordingly cheaper (Table 6).

The statuary soil sampling methods were not developed for the purpose of recommendations for optimum control measures leading to maximum returns (integrated pest management). They are used, in combination with other control measures (e.g., sampling adhering soil) to ensure the position of the Netherlands on the export market of seed potatoes. Implicitly, these methods are not so efficient that too many farmers will be caught and not so inefficient that too many export lots will be contaminated. From a commercial point of view, the statutory sampling methods seem to be adequate, but a scientific foundation for these methods is lacking. Their effectiveness greatly depends on the willingness of the importing country to invest in checking import lots. In fact, many countries within the European Union do not even respond any more to G. rostochiensis contamination of import lots, because this nematode has been spread over all countries and sufficient resistant cultivars are available. However, in case of slight tension between member states of the European Union, only a slight increase of the intensity of sampling or of the fraction of lots sampled by the importing member will cause the detection (or an increase of detection) of G. pallida in lots of the exporting member.

The simulation model described in this article provides a possibility to develop sampling methods for detection of field infesta-

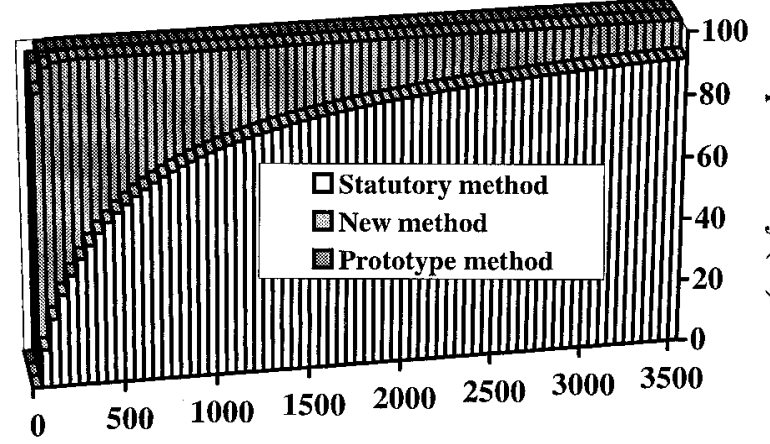

Population density of centre (cysts/kg)

Fig. 7. Overall detection probabilities with the statutory, prototype, and new (adapted 3) sampling methods of foci with central population densities ranging from 0 to 3,500 cysts per $\mathrm{kg}$. tions on demand for any set of conditions. For example, one can provide for statutory soil sampling methods with predefined characteristics (e.g., to facilitate that only a certain percentage of export lots will be contaminated or that foci above a certain threshold level will be detected) (Fig. 8).

The use of statutory soil sampling methods for detection and population density estimation poses a problem, because they were not developed and certainly not validated for those purposes. Farmers react with confusion when fields have been declared nematode-free as a result of statutory soil sampling, but research scientists, nonetheless, urge them to apply a more intensive sampling method. In 1989, the Dutch Plant Protection Service propagated the new sampling method by stating that control measures should be based on the new method, because the statutory soil sampling method does fulfil EPPO regulations but has no added value for the farmer (18).

The statutory soil sampling methods using a 200-ml bulk sample have such poor performances that only extremely large foci will be detected (Table 4). As a result, most detections will occur after infestation foci were already visible in the foregoing potato crop. At the moment of detection, these infestations will be so serious that farmers are likely to take chemical control measures. The new sampling method enables farmers to detect infestation foci when densities are low enough to grow (partially) resistant potato cultivars without yield reduction. Potato cyst nematodes can occur down to depths of up to $80 \mathrm{~cm}$ (6), as do potato roots (19); therefore, the effect of resistant cultivars greatly surpasses the effect of soil fumigation, because the latter only reduces population densities by an average of $60 \%$ and only in the upper 25 to $30 \mathrm{~cm}$ of the tilled zone $(3,6)$. It is possible to control potato cyst nematode infestation without severe crop losses by growing (partially) resistant potato cultivars in the usual rotations (1:3 and 1:4).

Since 1989 , the application area of the prototype sampling method as discussed in this paper increased rapidly to 13,000 ha per annum and, in 1994, soil fumigation was reduced by more than $80 \%$ in those areas where seed and ware potatoes are grown. As a result, the total reduction of the volume of nematicides throughout the Netherlands (including the starch potato cropping areas where soil fumigation was recently restricted to once in 4 years instead of once in 2 years) was $77 \%$ in 1995, far more than the $45 \%$ that was required for the year 1995 by the Multi-Year Crop Protection Plan (1).

If a focus is present in a field, but not detected with the new sampling method, its size can only be very small (Figs. 6 and 7). The probability of detection by statutory soil sampling is low (e.g., conditional overall detection probability 0.012 for the standard focus), whereas the probability of a yield reduction larger than $1 \%$ in the

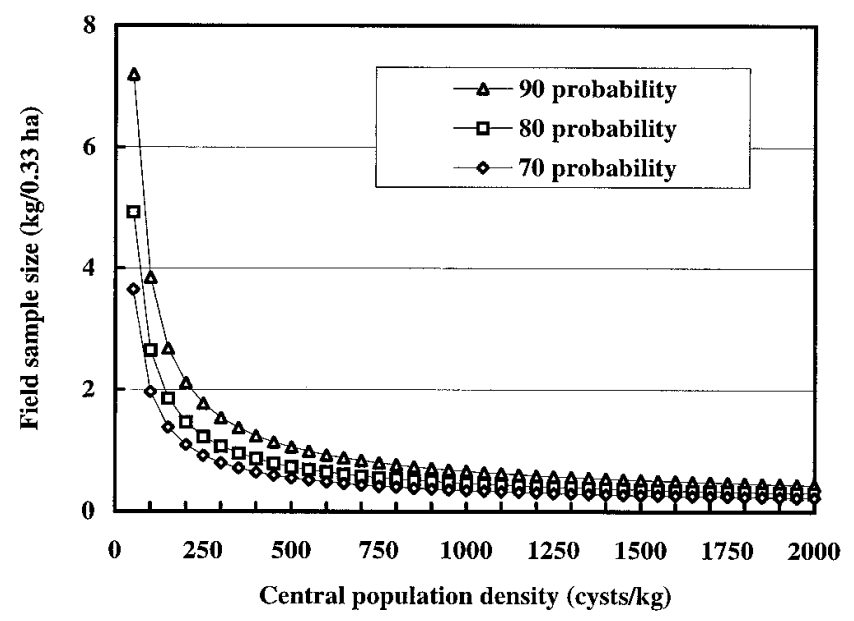

Fig. 8. Field sample sizes required to detect foci of increasing central population densities at average detection probabilities of 70, 80, and 90\%. Grid pattern of 5 by $5 \mathrm{~m}, l=0.77, w=0.55$, and $k=70$. 
next potato crop is nil. Using the new sampling methods, seed potato growers can take control measures before the infestation reaches a magnitude that causes it to be detected by any of the statutory soil sampling methods or becomes noticeable in seed potato lots. Sampling results can be used to calculate the size of the infestation detected and to generate advice for optimum control (7).

It is impossible to check the spread of potato cyst nematodes, but good detection methods allow the farmer to take immediate action to reduce infestations by G. rostochiensis with resistant cultivars and to contain infestations by $G$. pallida by growing (partially) resistant cultivars (8). Without soil sampling methods, no proper action can be taken.

Although the calculations presented in this article are based on foci in the Netherlands and the Dutch regulatory system, the models used and the conclusions obtained concerning sampling methods apply to other European countries and probably to all countries where potato cyst nematodes cause problems. Results of analyses of German and English detection methods (T. H. Been and C. H. Schomaker, unpublished data) only differ marginally, probably because one sampling approach was used as a template in most countries in Europe. However, the main aim is to present and emphasize the possibilities of a relatively simple but sound approach for development of sampling methods with known reliability to detect and used to manage nematode populations at chosen thresholds. These thresholds depend on factors such as cropping frequency of hosts and nonhosts in relation to risk of yield reduction and population dynamics, market conditions, export conditions, quality desired, and so on. This approach should not only be valid for potato cyst nematodes in the Netherlands, but generally useable in other countries, because parameters might differ but concepts remain the same. With necessary adaptations for differences in population dynamics and ecology, SAMPLE could be used as a tool for developing sampling methods on demand for other nematode species.

The models of foci used by SAMPLE that describe the result of focus expansion could be used for development of more dynamic models to simulate focus expansion in time and space. By adding models describing the active movement of free-living nematodes through the soil and their population dynamics, predictions could be made on how distribution patterns for nematode species such as Meloidogyne spp. or Pratylenchus spp. would develop. Some fields would have to be sampled to corroborate these results. This approach would probably speed up the development of sampling methods considerably.

\section{ACKNOWLEDGMENTS}

We thank D. van der Zaag (deceased), who challenged us to develop sampling methods for the detection of potato cyst nematodes with high and known probability; O. M. B. De Ponti and A. Riemens, who supported this research after its first positive results; J. W. Seinhorst (deceased), for many valuable discussions on this topic; and J. C. Zadoks, for critical reading of the manuscript.

\section{LITERATURE CITED}

1. Anonymous. 1991. Multi-Year Crop Protection Plan. Tweede Kamer der Staten-Generaal, Vergaderjaar 1990-1991, nrs. 3-4. Sdu-Uitgeverij, 'sGravenhage, the Netherlands.

2. Anonymous. 1995. Kwantitatieve informatie voor de Akkerbouw en de Groenteteelt in de Vollegrond. IKC, PAGV, DLV Publication no. 75. Proefstation voor de Akkerbouw en de Groenteteelt in de Vollegrond, Lelystad, the Netherlands.

3. Been, T. H., and Schomaker, C. H. 1987. Fumigation of marine-clay soils infested with potato cyst nematodes. Pages 410-411 in: 10th Triennial Conf. Eur. Assoc. Potato Res. (EAPR). Foldø, Hansen, Nielsen \& Rasmussen, Aalborg, Denmark.

4. Been, T. H., and Schomaker, C. H. 1996. A new sampling method for the detection of low population densities of potato cyst nematodes (Globodera pallida and G. rostochiensis). Crop Prot. 15:375-382.

5. Been, T. H., and Schomaker, C. H. 1998. Quantitative studies on the management of potato cyst nematodes (Globodera spp.) in the Netherlands. $\mathrm{Ph}$.D. thesis. Agricultural University, Wageningen, the Netherlands.

6. Been, T. H., and Schomaker, C. H. 1999. Soil fumigation of marine clay soils infested with Globodera pallida (Stone) and G. rostochiensis (Wollenweber) using 1,3-dichloropropene and an additional top soil treatment. Nematology 1:3-14.

7. Been, T. H., Schomaker, C. H., and Molendijk, L. 1996. Adviezen naar aanleiding van uitslagen van de intensieve AM-bemonstering voor de poot- en consumptieaardappelteelt in gebieden waar besmettingen pleksgewijs voorkomen. IPO-DLO Rapport no. 96-17. IPO-DLO, Wageningen, the Netherlands.

8. Been, T. H., Schomaker, C. H., and Seinhorst, J. W. 1995. An advisory system for the management of potato cyst nematodes (Globodera spp.). Pages 305-322 in: Nematology from Molecule to Ecosystem. F. J. Gommers and P. W. Th. Maas, eds. Dekker and Huisman, Wildervank, the Netherlands.

9. Bliss, C. I., and Fisher, R. A. 1953. Fitting the negative binomial distribution to biological data. Biometrics 9:176-200.

10. Bliss, C. I., and Owen, A. R. G. 1958. Negative binomial distributions with a common k. Biometrica 45:37-58.

11. Den Ouden, H. 1960. Periodicity in spontaneous hatching of Heterodera rostochiensis in the soil. Pages 101-105 in: Rep. 5th Int. Symp. Plant Nematol. Nematol Suppl. II. E. J. Brill, Leiden, the Netherlands.

12. Hofmeester, Y. 1990. Soil adhering by machines. Yearbook 1989/1990. Pages 289-292 in: PAGV Publication no. 58. Proefstation voor de Akkerbouw en de Groenteteelt in de Vollegrond, Lelystad, the Netherlands.

13. Schomaker, C. H., and Been, T. H. 1992. Sampling strategies for the detection of potato cyst nematodes; developing and evaluating a model. Pages 182-194 in: Nematology from Molecule to Ecosystem. F. J. Gommers and P. W. Th. Maas, eds. Dekker and Huisman, Wildervank, the Netherlands.

14. Schomaker, C. H., and Been, T. H. 1999. A model for infestation foci of potato cyst nematodes, Globodera rostochiensis and G. pallida. Phytopathology 89:583-590.

15. Seinhorst, J. W. 1982. The relationship in field experiments between population density of Globodera rostochiensis before planting potatoes and the yield of potato tubers. Nematologica 28:277-284.

16. Seinhorst, J. W. 1988. The estimations of densities of nematode populations in soil and plants. Växtskyddrapporter. Jordbruk 51. Swedish University of Agricultural Sciences, Research Information Center, Uppsala, Sweden.

17. Southey, J. F. 1973. Methods for detection of potato cyst nematodes. EPPO Bull. 4:463-473.

18. Toussaint, A. 1989. Opsporing aardappelmoeheid vooral een zaak voor de telers. Aardappelwereld 5:23-24.

19. Vos, J., and Groenwold, J. 1986. Root growth of potato crops on marineclay soils. Plant Soil 94:17-33.

20. Zadoks, J. C., and Van den Bosch, F. 1994. On the spread of plant disease: A theory on foci. Annu. Rev. Phytopathol. 32:503-521. 